\title{
C-Terminal Truncated Dystrophin Identified in Skeletal Muscle of an Asymptomatic Boy with a Novel Nonsense Mutation of the Dystrophin Gene
}

\author{
RYO SUMINAGA, YASUHIRO TAKESHIMA, HIROKO WADA, MARIKO YAGI, AND \\ MASAFUMI MATSUO
}

Department of Pediatrics [R.S., Y.T., M.Y., M.M.], Kobe University Graduate School of Medicine, Kobe 650-0017, Japan; and Department of Pediatrics [H.W.], Sakura Ryoikuen Hospital, Sanda 669-1357, Japan

\section{ABSTRACT}

\begin{abstract}
Mutations that cause premature stop codons in the dystrophin gene lead to a complete loss of dystrophin from skeletal muscle, resulting in severe Duchenne muscular dystrophy. Here, a Cterminally truncated dystrophin resulting from a novel nonsense mutation is shown for the first time to be localized to the muscle plasma membrane. An asymptomatic 8-y-old boy was examined for dystrophin in skeletal muscle because of high serum creatine kinase activity. Remarkably, no dystrophin labeling was seen with an MAb against the C-terminal domain, suggesting the presence of an early stop codon in the dystrophin gene. Labeling with an antibody specific to the $\mathrm{N}$-terminal domain, however, revealed weak, patchy, and discontinuous staining, suggesting limited production of a truncated form of the protein. Molecular analysis revealed a novel nonsense mutation $(\mathrm{Q} 3625 \mathrm{X})$ as a
\end{abstract}

result of a single nucleotide change in the patient's genomic DNA (C10873T), leaving $1.6 \%$ of dystrophin gene product unsynthesized at the $\mathrm{C}$ terminus. Dystrophin mRNA analysis did not show rescue of the nonsense mutation as a result of exonskipping by an alternative splicing mechanism. This is the first report of an asymptomatic dystrophinopathy with a nonsense mutation in the dystrophin gene. (Pediatr Res 56: 739-743, 2004)
Abbreviations
BMD, Becker muscular dystrophy
CK, creatine kinase
DMD, Duchenne muscular dystrophy

The severe Duchenne muscular dystrophy (DMD) and the more benign Becker muscular dystrophy (BMD) are allelic conditions characterized by progressive muscular degeneration and wasting accompanied by an elevation of serum creatine kinase $(\mathrm{CK})$. DMD is a rapidly progressive disease, with those affected starting to show muscle weakness at $\sim 4-5 \mathrm{y}$ of age and losing the ability to walk independently before the age of $12 \mathrm{y}$. $\mathrm{BMD}$ has a slower rate of progression; affected individuals remain ambulatory beyond the age of $16 \mathrm{y}$, and a few may lead near-normal lives (1).

DMD and BMD are caused by mutation of the dystrophin gene, which encodes a 14-kb mRNA that consists of 79 exons. The gene is the largest in humans and covers $>3000 \mathrm{~kb}$ on the $\mathrm{X}$ chromosome $(2,3)$. DMD and BMD are the most common genetic muscle diseases, affecting $>1$ in 3,500 male births. Two thirds of DMD/

Received June 11, 2003; accepted November 19, 2003

Correspondence: Masafumi Matsuo, M.D., Ph.D., Department of Pediatrics, Kobe University Graduate School of Medicine, 7-5-1 Kusunokicho, Chuo, Kobe 650-0017, Japan; e-mail: matsuo@kobe-u.ac.jp

This work was supported by grants from the Ministry of Education, Science and Culture of Japan and a Research Grant for Nervous and Mental Disorders from the Ministry of Health and Welfare of Japan.

DOI: 10.1203/01.PDR.0000142734.46609.43
BMD patients have deletion or duplication mutations of the dystrophin gene, and their clinical progression can be predicted by whether the deletion or duplication maintains (in-frame) or disrupts (out-of-frame) the translational reading frame (the readingframe rule) (4). Dystrophin is absent from skeletal muscle of DMD, because the dystrophin that is produced is truncated as a result of the premature stop codon and therefore is unstable, whereas in BMD, dystrophin that contains internal in-frame deletions produces protein that can be detected (5).

Single-base nonsense mutations have been suspected in DMD patients who do not show deletion/duplication mutations. However, detection of such defects in individual DMD patients is very difficult as a result of the large size of the gene. More than 100 nonsense mutations have been reported at various points over a 14-kb length of the dystrophin mRNA (http://www.dmd.nl). Despite this wide variation in coding potential (0-98.6\% of the full-length protein), these truncating mutations are associated with a surprisingly uniform severity of the DMD phenotype (6). However, a limited number of single-base nonsense mutations have been reported in patients with mild BMD that showed skipping of the exon encoding the mutation, thus producing an in-frame mRNA (7-11). 
Dystrophin is a cytoskeletal protein that is implicated in membrane stability and in communication between the extracellular matrix and the inner cytoskeleton $(12,13)$. The protein, which consists of 3685 amino acids, is divided into four distinct domains: an N-terminal domain, a large rod-like domain of 24 spectrin-like repeats that occupies $>70 \%$ of its length, a cysteine-rich domain, and, finally, a C-terminal domain $(2,14)$. Studies conducted on DMD/BMD patients suggest that the $\mathrm{N}$-terminal, cysteine-rich, and $\mathrm{C}$-terminal domains are essential for dystrophin's function $(15,16)$. Notably, the C-terminal domain, which consists of 416 amino acids encoded by 13 exons, shows sequence similarity with only two other dystrophin-related proteins and is considered to exert dystrophin's specific function $(14,17,18)$. In fact, in-frame deletions that extend into the $\mathrm{C}$-terminal domain have been reported to result in DMD, whereas large in-frame deletions of the rod domain result in BMD (16).

Here we report a C-terminally truncated dystrophin caused by a mutation in an asymptomatic boy with high CK activity. We propose that nonsense mutations of the dystrophin gene can result in a wide variety of clinical phenotypes.

\section{METHODS}

Case. The proband (KUDN 02765682) was an 8-y-old boy. His family history disclosed no neuromuscular disease. He started to walk independently at $1 \mathrm{y}$ of age, and his motor development was normal. He had a history of transient muscle weakness. At the age of $3 \mathrm{y}$, he complained of pain in the lower legs without any predisposing signs or symptoms and lost the ability to stand up and walk by himself. His serum CK was found to be $4901 \mathrm{IU} / \mathrm{L}$ (normal $<169 \mathrm{IU} / \mathrm{L}$ ). The muscle weakness persisted for $1 \mathrm{wk}$ but disappeared spontaneously and completely.

During the following period, his serum CK remained elevated but showed a strong fluctuation in value, ranging from 1,607 to 21,100 IU/L. Despite his high CK, he did not show any muscle weakness. At the age of $5 \mathrm{y}$, he was referred to Kobe University Hospital for examination of his elevated serum CK activity. His mental development was normal. On physical examination, there was no Gower's sign, walking abnormality, or pseudohypertrophy of the legs. An electromyogram disclosed myogenic changes. A chest $\mathrm{x}$-ray, electrocardiography, and echocardiography failed to reveal cardiac abnormalities. To clarify the cause of the elevation in serum CK and myogenic pattern in electromyogram, a quadriceps muscle biopsy was carried out after obtaining informed consent. The protocols of this study were approved by our ethical committee.

Immunohistochemical analysis. The muscle biopsy sample was examined pathologically and immunohistochemically. An indirect immunofluorescence analysis was performed using three dystrophin antibodies that recognize the $\mathrm{N}$-terminal (NCL-Dys3), the rod (NCL-Dys1), and the C-terminal (NCLDys2) domains of dystrophin (Novocastra Laboratories, Newcastle upon Tyne, UK) $(5,19)$. Furthermore, utrophin, $\beta$-dystroglycan, $\gamma$-sarcoglycan (Novocastra Laboratories Ltd, Newcastle upon Tyne, UK), laminin $\alpha 2$ (Chemicon Interna- tional Inc., Temecula, CA), and $\alpha$-dystroglycan (Upstate Biotechnology, Lake Placid, NY) were also stained using their respective antibodies. Control skeletal muscle tissue was obtained with informed consent and was simultaneously stained with the same panel of antibodies. Western blot analysis of dystrophin using an MAb that recognizes the C-terminal domain was performed by Athena Diagnostics (Worcester, MA).

Analysis of the dystrophin gene. For mutational analysis of the dystrophin gene, blood samples were obtained from the index case and family members after obtaining informed consent. DNA was isolated by standard phenol-chloroform extraction methods. For screening for deletion mutations, 19 deletion-prone exons were amplified from the genomic DNA by PCR essentially according to methods described previously (20). Southern blot analysis using dystrophin cDNA as a probe was performed with HindIII restriction enzyme-digested DNA as a template, as described by Koenig et al. (21). For analyzing genomic mutations, the region that encompasses exon 76 was amplified by PCR with g76F:5'-GGAGGGCTTCTAAAGTAGG-3' as the forward primer and g76r:5'-ATGTCCCTGTAATACGACTCTACC-3' as the reverse primer under conditions described elsewhere (20).

Analysis of dystrophin mRNA. Reverse-transcription PCR (RT-PCR) was used to analyze the dystrophin mRNA expressed in lymphocytes or skeletal muscle as described by Roberts et al. $(22,23)$. Full-length dystrophin cDNA was amplified as 10 separate, partially overlapping fragments and sequenced directly. For obtaining a fragment showing aberrant splicing, including exon 76 skipping, a region that encompasses exons 70-79 was amplified using a forward primer corresponding to a segment of exon 70 (70f:5'-CAGGAGAAGATGTTCGAGAC-3') and a reverse primer complementary to a segment of exon 79 (5f:5'-ATCATCTGCCATGTGGAAAAG-3').

Sequencing of the amplified product. The amplified product was purified and subjected to sequencing either directly or after subcloning into a pT7 blue T vector (Novagen, Madison, WI) (24). The DNA sequence was determined using an automated DNA sequencer (model 373A; Applied Biosystems, Foster City, CA).

\section{RESULTS}

For elucidating the cause of the elevation in serum CK, the biopsied muscle sample was examined pathologically. Microscopic examination disclosed slight dystrophic changes such as size variation in muscle fibers, fibers with central nuclei, and degenerated and regenerated fibers. Immunofluorescence staining for dystrophin revealed a complete absence of C-terminal domain labeling (Fig. 1). In contrast, both N-terminal and rod-domain staining was weak, patchy, and discontinuous along the plasma membrane (Fig. 1). These findings clearly indicated dystrophinopathy, but the patterns of dystrophin staining were not typical for either DMD or BMD. Western blot analysis of dystrophin using an antibody that recognizes the C-terminal domain of dystrophin revealed no significant bands (data not shown). These staining patterns indicate that a nonsense mutation in dystrophin is present in this patient, leading to production of a protein truncated somewhere up- 


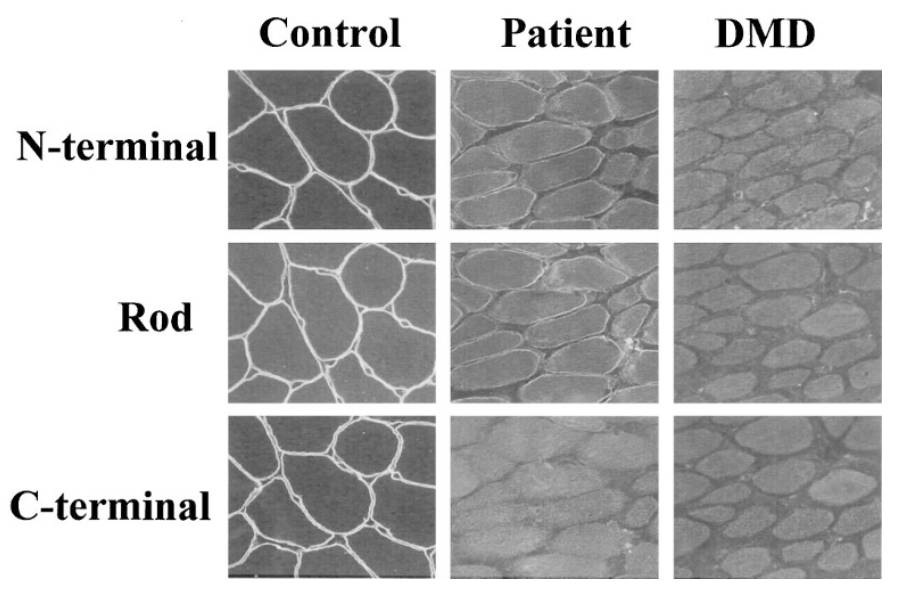

Figure 1. Immunofluorescence staining of biopsied muscle for dystrophin. The biopsied muscle was stained for dystrophin using antibodies against the $\mathrm{N}$-terminal, rod, and C-terminal domains. Staining of N-terminal and rod domains was weak, patchy, and discontinuous. In contrast, no reactive material was visualized for the C-terminal domain (patient). In unaffected individuals, all domains were clearly stained along the plasma membrane (control) but not in DMD.

stream of the C-terminal epitope recognized by the aforementioned antibody.

For clarifying the molecular pathogenesis of the abnormal dystrophin, the dystrophin gene was scanned for mutations. Neither PCR amplification of 19 selected exons nor Southern blot analysis of the dystrophin gene revealed any gross gene rearrangements. The possibility of deletion mutation therefore seemed unlikely. To find a single-base mutation, we analyzed dystrophin mRNA extracted from peripheral lymphocytes using RT-PCR as described previously (22). Ten fragments covering the full-length dystrophin cDNA could be amplified as normal-sized products. Direct sequencing of a fragment that encompasses exons 70-79 disclosed a single nucleotide change: a transition from a cytosine to a thymine at nucleotide 10873 (C10873T) in exon 76 (14). The same nucleotide change (C10873T) was present not only in his muscle dystrophin mRNA (Fig. 2) but also in his genomic DNA (data not shown) (25). His mother was found to be a carrier of the same mutation (data not shown). Because sequencing of other fragments of dystrophin cDNA disclosed no other significant nucleotide changes, it was concluded that this mutation (C10873T) is the cause of the dystrophinopathy. The nucleotide change converted a CAG codon, which encodes glutamine at the 3625th amino acid position, to a stop TAG codon (Q3625X; Fig. 2). Therefore, a truncated dystrophin lacking 60 amino acids at its $\mathrm{C}$ terminus (1.6\% of the total dystrophin sequence) was expected to be produced.

This truncation of dystrophin is compatible with the failure of the C-terminus-specific antibody to label the protein (Fig. 1 ), because this antibody recognizes amino acids $3669-3685$, an epitope that is downstream of the premature stop codon (Q3625X). However, that dystrophin did stain positively with antibodies against its $\mathrm{N}$-terminal and rod domains (Fig. 1) does not seem consistent with this truncation mutant, because other truncated dystrophin mutants have been found to be very unstable and undetectable immunohistochemically $(4,6)$. In
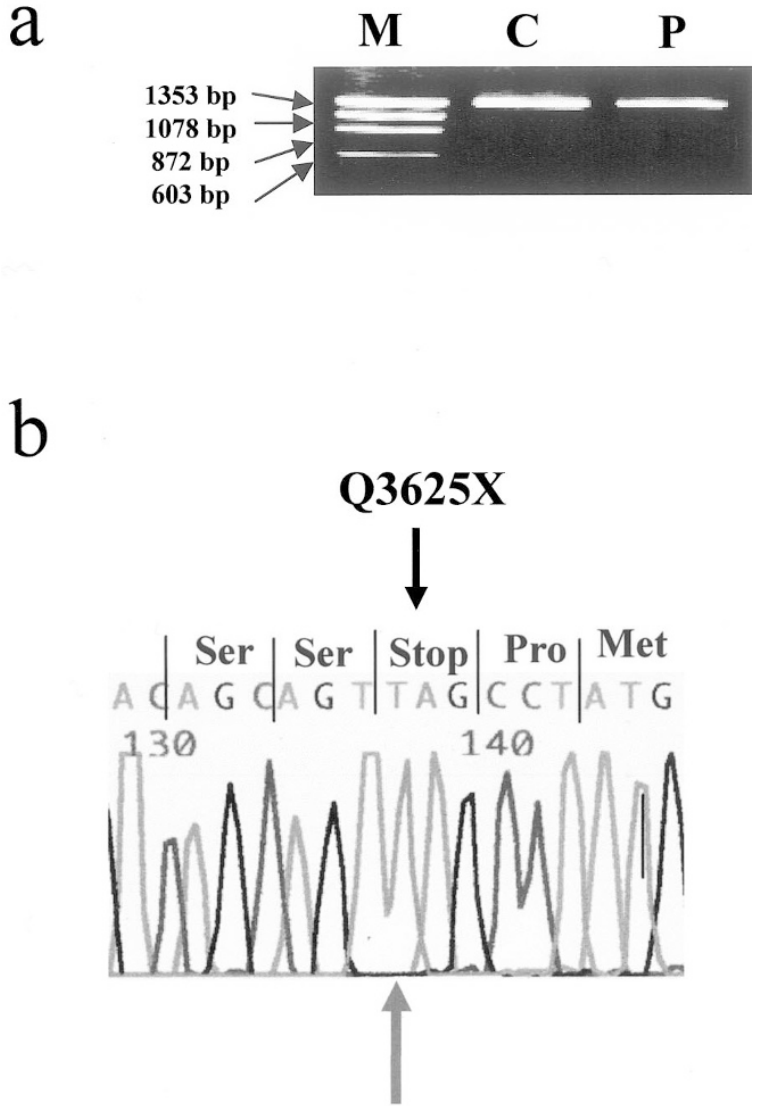

C10873T

Figure 2. Analysis of dystrophin mRNA prepared from muscle. (A) The amplified product encompassing exons $70-79$ is shown. One clearly visible product was obtained from the index case $(\mathrm{P})$, and the size of the amplified product is the same as that of the control (C). M refers to a DNA size marker, HaeIII-digested $\phi X 174$ DNA. (B) Nucleotide sequence around the mutation site. Direct sequencing of the amplified product disclosed a single nucleotide change from $\mathrm{C}$ to $\mathrm{T}$ at nucleotide 10873 (C10873T). This nucleotide change converted a CAG codon to a TAG stop codon (Q3625X). Nucleotide and amino acid numbering are based on those presented by Koenig et al. (14).

other cases, it has been hypothesized that the positive staining of dystrophin is the result of rescue of nonsense mutations by exon skipping or aberrant splicing $(8,26)$. However, the RTPCR-amplified product encompassing exons 70-79 disclosed only one visible band upon agarose gel electrophoresis (Fig. 2). In addition, both direct sequencing and sequencing after subcloning the product confirmed the presence of normal exon structure, indicating that only one mRNA was produced from the mutated gene. These observations do not support the possibility of exon-76 skipping or aberrant splicing.

Although the patient in our case harbored a Q3625X nonsense mutation, his clinical phenotype was unusually mild. Utrophin, a dystrophin-related protein, has been proposed to compensate for the function of dystrophin (27). Therefore, overexpression of utrophin might account for the clinical phenotype seen in the present case. The expression of utrophin was studied in muscle (Fig. 3) and was not found to be elevated in the index case in comparison with that typically seen in DMD. Therefore, enhanced expression of utrophin does not seem, to be modifying the clinical phenotype. Furthermore, the dystro- 


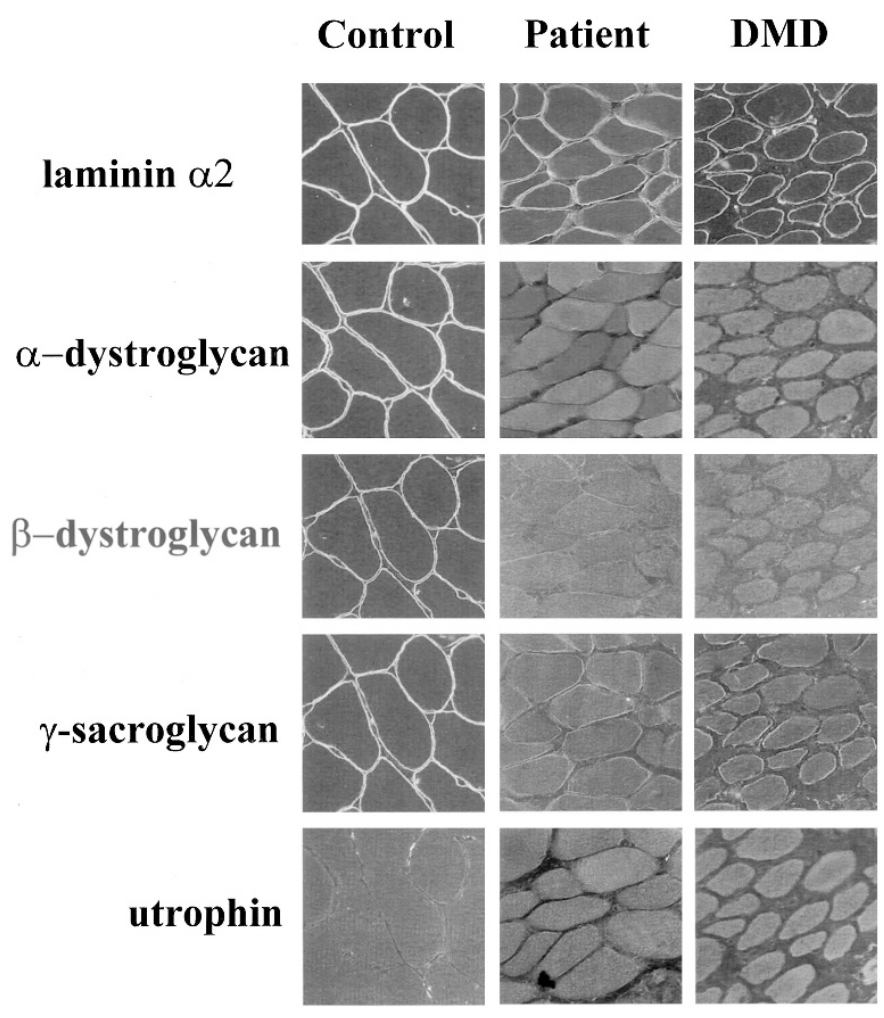

Figure 3. Immunofluorescence staining for dystrophin-associated and dystrophin-related proteins. The dystrophin-associated proteins $\alpha$ - and $\beta$-dystroglycan, $\gamma$-sarcoglycan, and laminin $\alpha 2$ were labeled with immunofluorescence. The staining patterns seen in the patient's muscle were similar to those observed in DMD. Also as in DMD, no labeling was seen for utrophin, a dystrophin-related protein.

phin-dystroglycan axis was examined (Fig. 3). Laminin $\alpha 2$, an extracellular matrix protein, stained weakly. Neither $\alpha$-dystroglycan, an extracellular $\beta$-dystroglycan-binding protein, nor $\beta$-dystroglycan, a transmembrane dystrophin-binding protein, was stained. $\gamma$-Sarcoglycan, a member of the sarcoglycan complex, was stained very weakly. All of these staining patterns were similar to those found in DMD (Fig. 3), indicating no difference in the stabilization of the dystrophindystroglycan axis from that observed in DMD (Fig. 3). Therefore, no explanation for the mild phenotype was obtained through studies of protein staining.

\section{DISCUSSION}

A novel nonsense mutation (Q3625X) in the dystrophin gene was identified in a Japanese boy who was as yet asymptomatic at the age of $8 \mathrm{y}$. Although a severe DMD phenotype would be expected to develop from his mutation type, his clinical course has been extraordinarily mild. The case has raised an important question to be answered: What is the mechanism that determines the severity of the dystrophic phenotype?

A somatic mosaic for a nonsense mutation has been shown to attenuate the clinical phenotype (28). However, this possibility seems to be excluded in the index case for the following reasons: 1) the mutation was inherited through the mother, and 2) a single genomic clone harboring $\mathrm{C} 10873 \mathrm{~T}$ was obtained not only from his lymphocytes but also from his muscle (data not shown). To rule out this possibility unequivocally, it is necessary to examine other muscle tissues, but this has not yet been done.

Another possible attenuating mechanism would be the modification of mRNA by either exon skipping or aberrant splicing, which would remove the nonsense mutation and produce a more complete dystrophin mRNA. Examples of exon skipping have been reported in nonsense mutations identified in exons $25,27,29$, and 72 of the dystrophin gene (7-11), and aberrant splicing has been reported in intermediate dystrophinopathy (26). In our case, however, not only the RT-PCR product of dystrophin mRNA but also subcloning sequencing disclosed the existence of only one kind of mRNA consisting of a normal exon structure (Fig. 2). The possibility of either exon skipping or aberrant splicing thus was ruled out. Therefore, the discrepancy between genotype and phenotype could not be explained at the mRNA level.

Elevated expression of utrophin has been speculated to convert a severe phenotype to a mild one without affecting dystrophin expression (27). However, level of utrophin expression was the same in our case as in DMD (Fig. 3). Furthermore, the staining of proteins encompassing the dystrophindystroglycan axis was identical to that seen in DMD (Fig. 3). These similarities show that protein-level changes do not underlie the observed phenotypic differences.

The truncated dystrophin produced in the index case seems to be unusually stable, as demonstrated by the weak but significant staining of the $\mathrm{N}$-terminal and rod domains (Fig. 1). This may be because the truncated dystrophin retains functionally important binding sites, such as actin binding sites in the $\mathrm{N}$-terminal and rod domains $(29,30)$, a $\beta$-dystroglycan binding site in the cysteine-rich domain (31), and syntrophin and dystrobrevin binding sites and a phosphorylation site in the C-terminal domain (Fig. 4) (32-35). In fact, it has been dem-

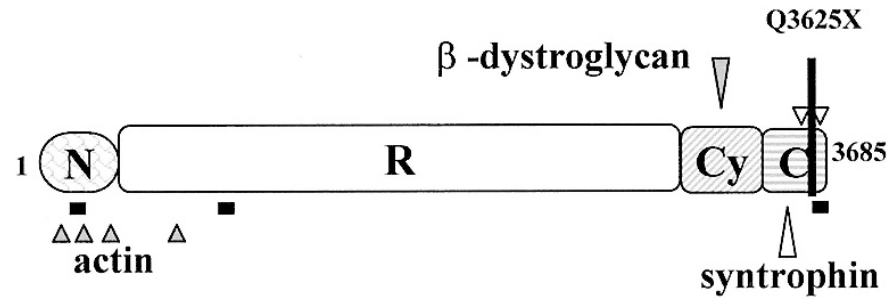

Figure 4. Dystrophin domain structure. Dystrophin consists of 3685 amino acids and is divided into four domains: the $\mathrm{N}$ terminus (box $\mathrm{N}$ ), the rod (box $\mathrm{R}$ ) and cysteine-rich (box $\mathrm{Cy}$ ) domains, and the $\mathrm{C}$ terminus (box $\mathrm{C}$ ). Three actin-binding sites have been identified in the $\mathrm{N}$ terminus (AB1 18-37 amino acids, ABS3 86-120 amino acids, and ABS2 128-149 amino acids), and one site (amino acids 1416-1880) has been found in the rod domain (all four sites indicated by arrowheads). In the cysteine-rich domain (amino acids 3115 326), dystrophin interacts with transmembrane $\beta$-dystroglycan (inverted triangle), which in turn binds to $\alpha$-dystroglycan. Syntrophin binds to a region in the C-terminal domain (3446-3481; open triangle), and a serine at the 3552nd residue and threonine at the 3675 th residue serve as phosphorylation sites (open arrowheads). Antibodies that recognize the N-terminal, rod, and Cterminal domains react to amino acid residues 321-494, 1181-1388, and 3669-3685, respectively (bars). The novel nonsense mutation (Q3625) is located at the end of the C-terminal domain (vertical bar). Numbers at both ends of the boxes indicate amino acid residues. The figure is not drawn to scale. 
onstrated that dystrophin lacking the amino acids encoded by exons $71-78$ is stable in muscle membranes of the $m d x$ mouse, an animal model of DMD (36). However, this hypothesis is not supported by a previous report that Q3625X, a nonsense mutation just 10 amino acids downstream of the one reported here (Q3635X), gave rise to clinically typical DMD (6) (Fig. 4). Furthermore, examination of laminin alpha $2, \alpha$ - and $\beta$-dystroglycans, and $\gamma$-sarcoglycan disclosed no difference in their staining patterns between our case and DMD (Fig. 3), indicating that augmented stabilization of these proteins does not contribute to the mildness of the phenotype. Clearly, further study is required to clarify these complex results.

Activation of transcription of the dystrophin gene may lead to overproduction of dystrophin mRNA. It has been proposed that an abnormality in a transcription factor(s) or in its binding site in the promoter of the dystrophin gene is a factor in phenotypic severity. In fact, mutation of the MYF6 gene results in a severe phenotype of BMD (37). However, modifier(s) that make the phenotype mild have not been reported to date $(38,39)$, although $m d x$ mice characterized by dystrophin deficiency do not show a severe DMD phenotype (40). We are now following up the index case, and a future study analyzing not only the dystrophin gene but also other genes may clarify the molecular mechanism explaining his mild phenotype.

\section{REFERENCES}

1. Emery AEH 1993 Duchenne Muscular Dystrophy. Oxford University Press, Oxford, pp $26-44$

2. Ahn AH, Kunkel LM 1993 The structural and functional diversity of dystrophin. Nat Genet 3:283-291

3. Nishio H, Takeshima Y, Narita N, Yanagawa H, Suzuki Y, Ishikawa Y, Minami R, Nakamura H, Matsuo M 1994 Identification of a novel first exon in the human dystrophin gene and of a new promoter located more than $500 \mathrm{~kb}$ upstream of the nearest known promoter. J Clin Invest 94:1037-1042

4. Monaco AP, Bertelson CJ, Liechti-Gallati S, Moser H, Kunkel LM 1988 An explanation for the phenotypic differences between patients bearing partial deletions of the DMD locus. Genomics 2:90-95

5. Arahata K, Ishiura S, Ishiguro T, Tsukahara T, Suhara Y, Eguchi C, Ishihara T, Nonaka I, Ozawa E, Sugita H 1988 Immunostaining of skeletal and cardiac muscle surface membrane with antibody against Duchenne muscular dystrophy peptide. Nature 333:861-863

6. Prior TW, Bartolo C, Pearl KP, Papp AC, Snyder PJ, Sedra MS, Burghes AHM, Mendell JR 1995 Spectrum of small mutations in the dystrophin coding region. Am J Hum Genet 57:22-33

7. Barbieri AM, Soriani N, Ferlini A, Michelato A, Ferrari M, Carrera P 1996 Seven novel additional small mutations and a new alternative splicing in the human dystrophin gene detected by heteroduplex analysis and restricted RT-PCR heteroduplex analysis of illegitimate transcripts. Eur J Hum Genet 4:183-187

8. Shiga N, Takeshima Y, Sakamoto H, Inoue K, Yokota Y, Yokoyama M, Matsuo M 1997 Disruption of the splicing enhancer sequence within exon 27 of the dystrophin gene by a nonsense mutation induces partial skipping of the exon and is responsible for Becker muscular dystrophy. J Clin Invest 100:2204-2210

9. Melis MA, Muntoni F, Cau M, Loi D, Puddu A, Boccone L, Mateddu A, Cianchetti C, Cao A 1998 Novel nonsense mutation (C->A nt 10512) in exon 72 of dystrophin gene leading to exon skipping in a patient with a mild dystrophinopathy. Hum Mutat 1(suppl):S137-S138

10. Ginjaar IB, Kneppers AL, v d Meulen JD, Anderson LV, Bremmer-Bout M, van Deutekom JC, Weegenaar J, den Dunnen JT, Bakker E 2000 Dystrophin nonsense mutation induces different levels of exon 29 skipping and leads to variable phenotypes within one BMD family. Eur J Hum Genet 8:793-796

11. Fajkusova L, Lukas Z, Tvrdikova M, Kuhrova VV, Hajek J, Fajkus J 2001 Novel dystrophin mutations revealed by analysis of dystrophin mRNA: alternative splicing suppresses the phenotypic effect of a nonsense mutation. Neuromuscul Disord 11:133-138

12. O'Brien KF, Kunkel LM 2001 Dystrophin and muscular dystrophy: past, present, and future. Mol Genet Metab 74:75-88

13. Burton EA, Davies KE 2002 Muscular dystrophy-reason for optimism? Cell 108:5-8
14. Koenig M, Monaco AP, Kunkel LM 1988 The complete sequence of dystrophin predicts a rod-shaped cytoskeletal protein. Cell 53:219-228

15. Passos-Bueno MR, Vainzof M, Marie SK, Zatz M 1994 Half the dystrophin gene is apparently enough for a mild clinical course: confirmation of its potential use for gene therapy. Hum Mol Genet 3:919-922

16. Takeshima $\mathrm{Y}$, Nishio H, Narita N, Wada H, Ishikawa $\mathrm{Y}$, Ishikawa $\mathrm{Y}$, Minami R, Nakamura H, Matsuo M 1994 Amino-terminal deletion of 53\% of dystrophin results in an intermediate Duchenne-Becker muscular dystrophy phenotype. Neurology $44: 1648-1651$

17. Matsumura K, Ervasti J, Ohlendieck K, Kahl S, Campbell K 1992 Association of dystrophin-related protein with dystrophin-associated proteins in $\mathrm{mdx}$ mouse muscle. Nature 360:588-591

18. Hugnot JP, Gilgenkrantz H, Vincent N, Chafey P, Morris GE, Monaco AP, BerwaldNetter Y, Koulakoff A, Kaplan JC, Kahn A, Chelly J 1992 Distal transcript of the dystrophin gene initiated from an alternative first exon and encoding a 75-kDa protein widely distributed in nonmuscle tissues. Proc Natl Acad Sci USA 89:7506-7510

19. Yagi M, Takeshima Y, Wada H, Nakamura H, Matsuo M 2003 Two alternative exons can result from activation of the cryptic splice acceptor site deep within intron 2 of the dystrophin gene in a patient with as yet asymptomatic dystrophinopathy. Hum Genet 112:164-170

20. Matsuo M, Masumura T, Nakajima T, Kitoh Y, Takumi T, Nishio H, Koga J, Nakamura H 1990 A very small frame-shifting deletion within exon 19 of the Duchenne muscular dystrophy gene. Biochem Biophys Res Commun 170:963-967

21. Koenig M, Hoffman EP, Bertelson CJ, Monaco AP, Feener C, Kunkel LM 1987 Complete cloning of the Duchenne muscular dystrophy (DMD) cDNA and preliminary genomic organization of the DMD gene in normal and affected individuals. Cell 50:509-517

22. Roberts RG, Barby TF, Manners E, Bobrow M, Bentley DR 1991 Direct detection of dystrophin gene rearrangements by analysis of dystrophin mRNA in peripheral blood lymphocytes. Am J Hum Genet 49:298-310

23. Matsuo M, Nishio H, Kitoh Y, Francke U, Nakamura H 1992 Partial deletion of a dystrophin gene leads to exon skipping and to loss of an intra-exon hairpin structure from the predicted mRNA precursor. Biochem Biophys Res Commun 182:495-500

24. Surono A, Takeshima Y, Wibawa T, Ikezawa M, Nonaka I, Matsuo M 1999 Circular dystrophin RNAs consisting of exons that were skipped by alternative splicing. Hum Mol Genet 8:493-500

25. Ito T, Takeshima Y, Yagi M, Kamei S, Wada H, Matsuo M 2003 Analysis of dystrophin mRNA from skeletal muscle but not from lymphocytes led to identification of a novel nonsense mutation in a carrier of Duchenne muscular dystrophy. J Neurol 250:581-587

26. Adachi K, Takeshima Y, Wada H, Yagi M, Nakamura H, Matsuo M 2003 Heterogous dystrophin mRNAs produced by a novel splice acceptor site mutation in intermediate dystrophinopathy. Pediatr Res 53:125-131

27. Blake DJ, Weir A, Newey SE, Davies KE 2002 Function and genetics of dystrophin and dystrophin-related proteins in muscle. Physiol Rev 82:291-329

28. Prior TW, Bartolo C, Papp AC, Snyder PJ, Sedra MS, Burghes AH, Mendell JR 1996 Nonsense mutations in a Becker muscular dystrophy and an intermediate patient. Hum Mutat 7:72-75

29. Jarrett HW, Foster JL 1995 Alternative binding of actin and calmodulin to multiple sites on dystrophin. J Biol Chem 270:5578-5586

30. Amann KJ, Renley BA, Ervasti JM 1998 A cluster of basic repeats in the dystrophin rod domain binds $\mathrm{F}$-actin through an electrostatic interaction. J Biol Chem 273:28419-28423

31. Pereboev AV, Ahmed N, thi Man N, Morris GE 2001 Epitopes in the interacting regions of beta-dystroglycan (PPxY motif) and dystrophin (WW domain). Biochem Biophys Acta 1527:54-60

32. Suzuki A, Yoshida M, Hayashi K, Mizuno Y, Hagiwara Y, Ozawa E 1994 Molecular organization at the glycoprotein-complex-binding site of dystrophin. Three dystrophin-associated proteins bind directly to the carboxy-terminal portion of dystrophin Eur J Biochem 220:283-292

33. Yang B, Jung D, Rafael JA, Chamberlain JS, Campbell KP 1995 Identification of alpha-syntrophin binding to syntrophin triplet, dystrophin, and utrophin. J Biol Chem 270:4975-4978

34. Blake DJ, Tinsley JM, Davies KE, Knight AE, Winder SJ, Kendrick-Jones J 1995 Coiled-coil regions in the carboxy-terminal domains of dystrophin and related proteins: potentials for protein-protein interactions. Trends Biochem Sci 20:133-135

35. Sadoulet-Pucchio HM, Rajala M, Kunkel LM 1997 Dystrobrevin and dystrophin: an interaction through coiled-coil motifs. Proc Natl Acad Sci USA 94:12413-12418

36. Crawford GE, Faulkner JA, Crosbie RH, Campbell KP, Froehner SC, Chamberlain JS 2000 Assembly of the dystrophin-associated protein complex does not require the dystrophin COOH-terminal domain. J Cell Biol 150:1399-1410

37. Kerst B, Mennerich D, Schuelke M, Stoltenburg-Didinger G, von Moers A, Gossrau R, van Landeghem FK, Speer A, Braun T, Hubner C 2000 Heterozygous myogenic factor 6 mutation associated with myopathy and severe course of Becker muscular dystrophy. Neuromuscul Disord 10:572-577

38. Hattori N, Kaido M, Nishigaki T, Inui K, Fujimura H, Nishimura T, Naka T, Hazama T 1999 Undetectable dystrophin can still result in a relatively benign phenotype of dystrophinopathy. Neuromuscul Disord 9:220-226

39. Davis DB, Delmonte AJ, Ly CT, McNally EM 2000 Myoferlin, a candidate gene and potential modifier of muscular dystrophy. Hum Mol Genet 9:217-226

40. Sicinski I, Geng Y, Ryder-Cook AS, Barnard EA, Darlison MG, Barnard PJ 1989 The molecular basis of muscular dystrophy in the mdx mouse: a point mutation. Science 244:1578-1580 